\title{
Matrixes of Risk and Alarm Levels in Rapid Flow
}

\author{
[ G. Ciaravino, C. Ciaravino ]
}

\begin{abstract}
The paper analyzes particular matrixes that facilitate an evaluation of the levels of risk and alarm in increasingly frequent and dangerous phenomena of rapid flow. This increased frequency and hazard is related to climate change and to environmental modifications caused by human interventions. In particular the paper analyzes matrixes that, by means of the assessment of a reduced number of simplified parameters, makes it possible to evaluate the levels of risk and of attention in the phenomena of slope instability. Finally the importance of the instrumental monitoring of the RTU (Reference Territorial Unities) is stressed in the context of civil protection planning.
\end{abstract}

Keywords-rapid flow, risk matrixes, alarm threshold, slope monitoring

\section{Introduction}

The complex study of rapid flows (both debris and mud flows) has increasingly attracted the attention of researchers [1-11] and technicians because of the growing frequency and hazard that this phenomenon has displayed in recent years [12].

This increased frequency and hazard is in part due to changes in the characteristics of the extreme events we have witnessed (climate change) but, above all, it is related to modifications in the hydrogeological and environmental balance caused by human interventions.

Public authorities responsible for land management, on the other hand, are interested in simple tools that can be easily applied in both technical and administrative terms in order to:

1) identify areas at real and/or potential risk;

2) determine technical standards for the assessment and design of structural and non-structural interventions for risk mitigation; plans.

3) set up alarm systems to integrate into civil protection

Giulio Ciaravino

Full Professor, University of Naples Federico II, Italy

Cristiano Ciaravino

Engineer + MEng, Italy
The present paper analyzes particular matrixes that, although characterized by intrinsic limitations, can assess a reduced number of simplified parameters in order to facilitate an evaluation of the levels of risk and of attention in the phenomena of slope instability concerning single Reference Territorial Unities (RTU).

\section{Risk assessment matrixes}

The risk parameter is normally identified in the value of the damage that may result in elements distinguished by a given vulnerability to the occurrence of an event of given hazard. Risk evaluation is thus a hierarchical assessment that is not absolute but relative, since it is linked to the nature and vulnerability of the various elements in play and also to the particular event and its level of hazard. Therefore it is possible to write the following equation:

$$
R=H \cdot V \cdot E
$$

where (UNESCO definitions and hypothesis of limited spatial propagation of the phenomenon):

- $\quad R$ is the Total Risk: expected number of lives lost, persons injured, damage to property, or disruption of economic activity due to a particular natural phenomenon;

- $\quad H$ is the Natural Hazard: probability of occurrence within a specified period of time and within a given area of a potentially damaging phenomenon;

- $\quad V$ is the Vulnerability: degree of loss to a given element or set of elements at risk resulting from the occurrence of a natural phenomenon of a given magnitude; it is expressed on a scale from 0 (no damage) to 1 (total loss);

- $E$ is the Elements at Risk: population, properties, economic activities, including public services at risk in a given area; it is expressed, again under a simplified hypothesis, on a scale from 0 to 1 .

This hierarchy is normally based on the acknowledged primary value of human life and, as a result, the risk assessment matrixes are built on the interaction between the level of Specific Risk $P$ ( product $H \cdot \odot$ : expected degree of loss due to a particular natural phenomenon) and the exposed anthropic elements $E$. Therefore various levels of Specific Risk $P$ and the anthropic elements $E$ are identified in order to obtain the level of Total Risk $R$. In particular, the following four increasing levels of Specific Risk $P$ (moderate, medium, high, very high) can be determined for the RTU which are homogeneous in terms of morphological and lithological characteristics for the slope processes (Table 1 matrix): 
Proc. of the Third Intl. Conf. on Advances in Civil, Structural and Construction Engineering - CSCE 2015 Copyright (C) Institute of Research Engineers and Doctors, USA .All rights reserved.

ISBN: 978-1-63248-079-8 doi: 10.15224/ 978-1-63248-079-8-54

1) Pl (moderate), slopes characterized by factors predisposing for low-intensity evolutionary phenomena, medium-intensity inactive phenomena (inactive detrital mud fan), or medium/high intensity and low magnitude phenomena (very limited volume set in motion);

2) P2 (medium), slopes characterized by factors predisposing for medium-intensity evolutionary phenomena and high-intensity but medium magnitude phenomena;

3) P3 (high), slopes characterized by factors predisposing for high-intensity and high magnitude evolutionary phenomena, inactive rapid mudflow, active slow mudflow, slow mudflow supply area, quiescent mudflows, rapid flow supply area in predominantly clay soils, rapid flow in predominantly argillaceous marl soils;

4) P4 (very high), slopes characterized by rapid mudflow, quiescent rapid mudflow, rapid mudflow supply areas, highintensity and high-magnitude phenomena.

\begin{tabular}{|c|c|c|c|c|}
\hline & $V 1$ & $V 2$ & $V 3$ & $V 4$ \\
\hline H 1 & $P 1$ & $P 1$ & $P 2$ & P 2 \\
\hline H 2 & $P 1$ & $P 2$ & P 3 & P 3 \\
\hline H 3 & $P 2$ & $P 2$ & P 3 & $P 4$ \\
\hline H 4 & $P 2$ & P 3 & $P 4$ & $P 4$ \\
\hline
\end{tabular}

Table 1. Specific risk assessment matrix

The Elements at Risk $E$ is generally classified through the following criteria:

1) El (0.25), environmental heritage with substantial absence of anthropic infrastructure and activities;

2) E2 (0.50), scattered houses, network infrastructure and roads (motorways, main roads and local roads);

3) E3 (0.75), towns, areas with production facilities and important technological plants;

4) E4 (1.00), major cities and significant cultural heritage sites.

The risk assessment matrix set up using the above Specific Risk $P$ and Elements at Risk $E$ is shown in Table 2.

\begin{tabular}{|l|l|l|l|l|}
\cline { 2 - 5 } \multicolumn{1}{c|}{} & $E 1$ & $E 2$ & $E 3$ & $E 4$ \\
\hline$P 1$ & $R 1$ & $R 1$ & $R 2$ & $R 2$ \\
\hline$P 2$ & $R 1$ & $R 2$ & $R 3$ & $R 3$ \\
\hline$P 3$ & $R 2$ & $R 2$ & $R 3$ & $R 4$ \\
\hline$P 4$ & $R 2$ & $R 3$ & $R 4$ & $R 4$ \\
\hline
\end{tabular}

Table 2. Total risk assessment matrix
The matrix identifies the following levels of Total Risk $R$ :

1) $R l$ (moderate risk), areas in which expected anthropic and social damage is null, and the economic and environmental damage is slight; in these areas only phenomena of slight intensity and magnitude can be expected;

2) $R 2$ (medium risk), areas in which expected anthropic damage is still null, but there may be slight damage to buildings (without compromising their use), to network infrastructure and roads (without jeopardizing their functionality) and to the environment (without interrupting economic activities); in these areas low-intensity phenomena (setting even large volumes in motion) and medium intensity and medium magnitude phenomena can be expected;

3) $R 3$ (high risk), areas where there is a possibility of human injury (but without loss of lives), damage to buildings (seriously compromising their use), to infrastructure (causing reduced functionality), interruption of socio-economic activities and significant damage to the environment; in these areas high-intensity and medium magnitude events can be expected;

4) $R 4$ (very high risk), areas in which there may be loss of human life, serious damage to buildings (including collapse), to infrastructure (with loss of functionality) and to the environment, with the destruction of socio-economic activities; in these areas events of high or very high intensity and magnitude can be expected (rapid mudslides).

\section{Alarm threshold assessment matrixes}

A basic technical and administrative action lies in the setting up of alarm systems that come into operation prior to the occurrence of slide phenomena for use as part of civil protection plans.

A number of predictive methods aiming to support such an action have been proposed in recent years, the most innovative and propitious of which appear to be those which combine soil stability models with water infiltration and transport models [13-17]:

A slope stability model is generally based on the validity of Mohr-Coulomb's law which defines the soil's shear strength $\tau$ :

$$
\tau=c_{\tau}+\left(\sigma-p_{W}\right) \cdot \operatorname{tag} \Phi
$$

In this equation:

- $\quad c_{\tau}$ is the soil's effective cohesion;

- $\quad \sigma$ is the normal stress;

- $\quad p_{W}$ is the interstitial water pressure;

- $\Phi$ is internal friction angle. 
Proc. of the Third Intl. Conf. on Advances in Civil, Structural and Construction Engineering - CSCE 2015

Copyright (C) Institute of Research Engineers and Doctors, USA .All rights reserved.

ISBN: 978-1-63248-079-8 doi: 10.15224/ 978-1-63248-079-8-54

Neglecting $c_{\tau}$ (in favour of safety), the previous relation yields [18]:

$\left(\rho_{S} \cdot g \cdot z \cdot \cos \theta\right) \cdot \sin \theta=\left(\rho_{S} \cdot g \cdot z \cdot \cos 2 \theta-\rho_{W} \cdot g \cdot h \cdot \cos 2 \theta\right) \cdot \operatorname{tag} \Phi(3)$

In this equation:

- $\quad \rho_{S}$ and $\rho_{w}$ are the soil and water densities;

- $\quad g$ is the acceleration due to gravity;

- $\quad z$ is the height of the soil layer;

- $\theta$ is the slope;

- $\quad h$ is the groundwater level (with reference to $z$ ).

By obtaining the $h / z$ ratio from this relation, instability conditions are highlighted even in the event of unsaturated soil:

$$
h / z=\left(\rho_{S} / \rho_{W}\right) \cdot(1-\operatorname{tag} \theta / \operatorname{tag} \Phi)
$$
when:

In particular, stability depends on the groundwater level

$$
\left(1-\rho_{W} / \rho_{S}\right) \cdot \operatorname{tag} \Phi<\operatorname{tag} \theta<\operatorname{tag} \Phi:
$$

1) the soil layer is stable if :

$$
\left(1-\rho_{W} / \rho_{S}\right) \cdot \operatorname{tag} \Phi<\operatorname{tag} \theta<\operatorname{tag} \Phi
$$

and

$$
h / z<(1-\operatorname{tag} \theta / \operatorname{tag} \Phi) \cdot \rho_{S} / \rho_{W}
$$

2) the soil layer is unstable if :

$$
\left(1-\rho_{W} / \rho_{S}\right) \cdot \operatorname{tag} \Phi<\operatorname{tag} \theta<\operatorname{tag} \Phi
$$

and

$$
h / z>(1-\operatorname{tag} \theta / \operatorname{tag} \Phi) \cdot \rho_{S} / \rho_{W} .
$$

It can also be noted that displacement processes are triggered when rainfall causes the slope's surface layer to become heavier and seepage determines neutral pressures that cancel out the cohesion and friction forces.

It therefore appears to be initially useful to determine a matrix for the assessment of a warning threshold $A$ (further subdivided into four fields, from moderate to very high) linked to a weather event severity parameter $I$, a function of the rainfall intensity, and a soil state and property parameter $F$, a function of the $h / z$ ratio. These parameters should be calibrated to every single RTU (characterising the geometry and the hydrological properties of the soil), which calls for specific investigations.

Proceeding concisely (taking into account the values that most frequently arise in events triggering displacement phenomena on the slopes of basins in the Mediterranean), for the matrix reported in Table 3, we can hypothesize assigning the $I$ parameter with the values $I I, I 2, I 3$ and $I 4$, when the rainfall intensity thresholds of $10,20,50$ and $100 \mathrm{~mm} / \mathrm{h}_{\mathrm{r}}$ are respectively reached $[18,19]$.

\begin{tabular}{|l|c|c|c|c|}
\cline { 2 - 5 } \multicolumn{1}{c|}{} & I 1 & I 2 & I 3 & I 4 \\
\hline F 1 & $A 1$ & $A 1$ & $A 2$ & $A 3$ \\
\hline F 2 & $A 1$ & $A 2$ & $A 3$ & $A 3$ \\
\hline$F 3$ & $A 2$ & $A 3$ & $A 3$ & $A 4$ \\
\hline F 4 & $A 3$ & $A 3$ & $A 4$ & $A 4$ \\
\hline
\end{tabular}

Table 3. Alarm threshold assessment matrix

The more complex $F$ parameter can be assigned the following values as a preliminary step and in the absence of specific assessments [20]:

- $\quad F 1$ corresponding to the ratio $h / z<0.25$;

- $\quad F 2$ corresponding to $0.25 \leq h / z<0.50$;

- $\quad F 3$ corresponding to $0.50 \leq h / z<0.75$;

- $\quad F 4$ corresponding to $h / z \geq 0.75$.

\section{Iv. Discussion and further observations}

Use of this matrix is complementary to the installation, in the single RTU, of monitoring instruments (rain gauges and piezometers) which are needed (in addition to the characterization of the soil's geometry and hydrological properties) in order to calibrate the parameters $I$ and $F$ and to define warning thresholds in the civil protection plan.

The utility of and necessity for monitoring instruments on slopes in limit conditions are highlighted by the results obtained in a piezoemetric and pluviometric measurements campaign lasting five years and conducted on a sliding slope stabilized by means of drainage operations (Fig. 1) [21]. 
Proc. of the Third Intl. Conf. on Advances in Civil, Structural and Construction Engineering - CSCE 2015 Copyright $(\odot$ Institute of Research Engineers and Doctors, USA .All rights reserved.

ISBN: 978-1-63248-079-8 doi: 10.15224/ 978-1-63248-079-8-54
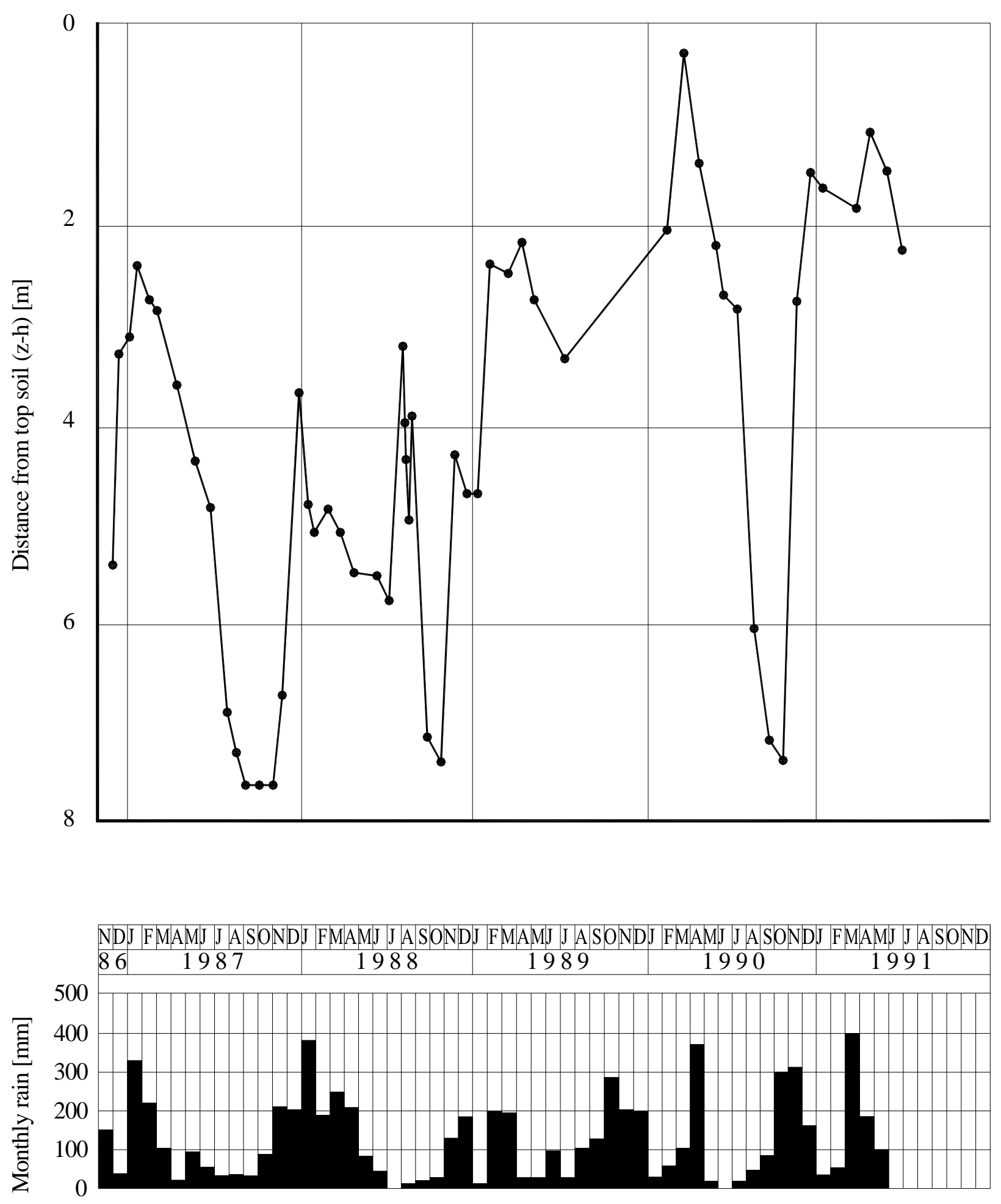

Figure 1. Piezometric and pluviometric measurements 
Analysis of the measurements taken in this case has also highlighted the considerable speed with which water levels rise in the piezometers after the weather events (a particular circumstance which is significant for stability and which may elude predictive models).

In general, this phenomenon may be determined by the presence of underground fissures, either pre-existing or which may open up without there being any visible signs on the slope; although they may appear to be closed on the surface, these provide a preferential route for water to move up from the subsoil and, therefore, give rise to instability which can only be detected in advance by appropriate instrumentation.

\section{v. Conclusions}

The methodological approach presented has made it possible to propose a concise instrument comprising easy-touse matrixes and which is practical in technical and administrative applications.

In conclusion, the main feature of these simplified matrixes lies in:

1) subdividing the area into zones with differing risk levels for technical and administrative purposes;

2) planning risk mitigation strategies by means of simple and substantially objective tests;

3) determining the economic and financial investments needed to safeguard the local area;

4) establishing guidelines and coordination strategies;

5) setting up warning systems with tests and instrumentation that can be read in time scales that are compatible with an alarm situation.

Analysis of some experimental on-site measurements has highlighted the importance of linking these matrixes to instrumental monitoring of the RTUs in order to achieve a sound predictive action and to define specific parameters for use in civil protection plans.

\section{References}

[1] T. Takahashi, "A mechanism of occurrence of mud-debris flow and their characteristics in motion", Disaster Prevention Institute Annals, 21, B-2, 1977.

[2] J. Jenkins, S.B. Savage, "A theory for rapid flow of identical, smooth, nerly elastic, spherical particles” J. Fluid Mech, Vol.130, pp. 186-202, 1983.

[3] P.C. Johnson, R. Jackson, "Frictional-collisional constitutive relations for granular materials with application to plane shearing", J. Fluid Mech, Vol.176, pp. 67-93, 1987

[4] T. Takahashi, "Debris-flow" IAHR Monograph, Balkema, Rotterdam, 1991.

[5] M. Tubino, S. Lanzoni, "'Rheology of debris flow: experimental observations and modelling problems" Excerta, vol.7, CUEN, Napoli, pp.210-236, 1994.
[6] R.M. Iverson, "The physics of debris flow" Review of Geophysics 35 (3), pp. 245-296,1997.

[7] G. Di Silvio, C. Gregoretti, "Gradually varied debris flow along a slope", Proceedings of First International Conference On Debris Flow: Hazards, Mitigation, ASCE, San Francisco ,1997.

[8] A. Armanini, L. Fraccarollo, L. Guarino, R. Martino and Y. Bin, "Experimentals analysis of the general features of uniform debris-flow over a loose bed", In: Wieczorek, G.F., Naeser, D., 2000 Eds, DebrisFlow Hazards Mitigation: Mechanics, Prediction and Assessment. A.A. Balkema, Rotterdam, 2000.

[9] D. Naser, "Debris-Flow Hazards Mitigation: Mechanics, Prediction and Assessment", A.A. Balkema, Rotterdam, 2000.

[10] F.M. Guadagno, P. Revellino, "Debris avalanches and debris flows of the Campania Region (southern Italy)", In: M. Jakob, O. Hungr, 2005 Eds, Debris-Flow Hazards and Related Phenomena. Praxis, Springer Berlin Heidelberg, 2005.

[11] T. Takahashi, "Debris Flow: Mechanics, Prediction and Countermeasures", s.l.: Taylor \& Francis, 2007.

[12] A.L. Zollo, G. Rianna, P. Mercogliano, P. Tommasi and L. Comegna L. "Validation of a simulation chain to assess climate change impact on precipitation induced landslides", Proceedings of World Landslide Forum 3, Beijing, 2-6 June, 2014.

[13] B. Sirangelo, P. Versace, "A real time forecasting model for landslides triggered by rainfall” Meccanica, 31, pp.73-85, 1996.

[14] D.R. Montgomery, W.E. Dietrich, "A physically based model for the topographic control on shallow landsliding", Water Resour. Res., 30, pp.1153-1171, 1998

[15] W.E. Dietrich, D.R. Montgomery, "Shalstab: a digital terrain model for mapping shallow landslide potential Gradually varied debris flow along a slope", NCASI Technical Report, 29 pp, February, 1998.

[16] R.M. Iverson, R.P. Denlinguer, R.G. La Husen and M. Logan, "Twophase debri-flow across 3-D terrain: Model prediction and experimental test” In: G.F. Wieczorek, D. NaeserAESER D.,2000 Eds, Debris-Flow Hazards Mitigation: Mechanics, Prediction and Assessment. A.A. Balkema, Rotterdam (2000).

[17] W.E. Dietrich, D. Bellugi and R. Real de Asua, "Validation of the shallow landslide model. Shalstab, for forest management" In: M.S. Wigmosta, S.J. Burges, 2001 Eds, Land Use and Watersheds: Human influence on hydrology and geomorphology in urban and forest areas, Amer. Geoph. Union, Water Science and Application, 2, pp.195-227, 2001.

[18] R. Rosso R., "Sulla valutazione dei fattori idrologici e geomorfici di innesco delle frane superficiali nei bacini montani", $28^{\circ}$ Convegno di Idraulica e Costruzioni Idrauliche; Potenza 16-19 settembre, 2002, (in Italian)

[19] F. Rossi, G.B. Chirico, "Definizione delle soglie pluviometriche di allarme", Dipartimento di Protezione Civile, GNDCI - Unità Operativa Università di Salerno Sub Unità di Idraulica e Costruzioni Idrauliche, 1998, (in Italian).

[20] G. Ciaravino, L. Ciaravino, G. Grimaldi, G. Lombardi, N. Maddaloni, C. Minotta and L.S. Sorvino, "Matrici per la valutazione dei livelli di rischio in debris flow" Giornale di Geologia Applicata. vol. 2 , pp. 9398, 2005, (in Italian).

[21] G. Ciaravino, G.B. Fenelli, "Analisi tramite osservazioni e rilievi di falda di un intervento di stabilizzazione di un corpo viario effettuato con drenaggi" $23^{\circ}$ Convegno di Idraulica e Costruzioni Idrauliche, Firenze 31 agosto - 4 settembre, 1992, (in Italian). 